\title{
Convergence in Spanish Public health expenditure: Has the decentralization process generated disparities?
}

\author{
Jesús Clemente ${ }^{\mathrm{a}}$, Angelina Lázaro-Alquézar ${ }^{\mathrm{b}}$, Antonio Montañés ${ }^{\mathrm{a}, *}$ \\ a Department of Economic Analysis, University of Zaragoza, Gran Vía 2, 50.005, Zaragoza, Spain \\ b Department of Applied Economics, University of Zaragoza, Gran Vía 2, 50.005, Zaragoza, Spain
}

\section{A R T I C L E I N F O}

\section{Article history:}

Received 27 September 2017

Received in revised form 15 June 2018

Accepted 5 March 2019

\section{JEL classification:}

C22

I10

I18

Keywords:

Health system

Public health expenditure

Convergence

pArtisan behavior

\begin{abstract}
A B S T R A C T
This study examines the per capita public health expenditures among the Spanish regions. To that end, we employ the database elaborated by the BBVA Fundation and IVIE (2013) which covers the years 1991-2010. We first test for the null hypothesis of convergence by employing the methodology proposed in Phillips and Sul (2007) in order to determine whether the evolution of the public health expenditures has followed a similar path across the Spanish regions. This methodology leads us to reject the null hypothesis of convergence, which implies the absence of a unique pattern of behavior in the evolution of the Spanish regional public health expenditures. Instead, we find several convergence clubs which reveal the existence of different patterns of behavior and serious disparities in the Spanish health system. When trying to determine the forces which drive the creation of these clubs, we also find some partisan behavior, in the sense that the longer a right-wing party governs, the lower the per capita public health expenditure in this region of Spain.
\end{abstract}

(C) 2019 Published by Elsevier B.V.

\section{Introduction}

Most of the articles devoted to the analysis of the evolution of health expenditure focus on the study of its determinants. The influence of the seminal paper of Newhouse [3] is unquestionable as is the importance of the Gross Domestic Product as the main explanatory factor of health expenditure, as Hartwig and Sturm [4] recognizes. Accordingly, we could expect two economies with similar health systems and per capita GDP to exhibit similar levels of health expenditure. However, this does not seem to be true in practice as we can easily observe differences in health expenditures. This result has opened a debate as to whether these expenditures converge towards a single pattern of behavior or, by contrast, diverge.

We can cite some papers where convergence in health expenditure is analyzed. Some of them consider an international framework, comparing the health expenditures of several countries. This is the case of the papers of Barros (1998) and, more recently, Panopoulou and Pantelidis [5] Villaverde et al. [6] and Payne et al. [7]. However, countries exhibit important differences in their health systems. To circumvent these differences, it seems

\footnotetext{
* Corresponding author.

E-mail address: amontane@unizar.es (A. Montañés).
}

advisable to analyze convergence in health expenditures from a regional point of view. The most relevant papers in this line are those of Wang [8] Apergis and Padhi [9] Panopoulou and Pantelidis [10] and Clemente et al. [11], all of them related to the US case. The overall conclusion of these papers is that the convergence hypothesis is rejected and that, consequently, the absolute regional convergence in health expenditure hypothesis cannot be accepted.

These disparities need to be explained, and we can employ a number of variables to that end, including institutional factors. In this line, we can cite the contributions of Potrafke [12] Herwartz and Theilen [13] Liang and Mirelman [14] and Bellido et al (2017). These papers find some evidence of the influence of the ideology of the governing party on health expenditure. Similarly, and more important for the present work, Costa-Font and Pons-Novell [15] note that the degree of political decentralization may move the health expenditure decision from the central to the regional or local government and the heterogeneity of the ideology of local governments may be higher and more persistent. A good, for example, health, could be treated very differently across different regions of a country depending on factors such as the ideology of the party in government. We consider that Spain is a paradigmatic case of this decentralization process and can provide a good example of the effect of institutional factors on the divergence of health expenditures. Therefore, the analysis of the Spanish regional public health expenditures can help us to understand how the implementation 
of different regional health policies may result in the generation of a heterogeneous health system.

Accordingly, the aim of this paper is to study whether the decentralization process has generated disparities in the Spanish health system, especially whether the evolution of the HEPC is significantly different across the Spanish regions, which may cause distortions in the Spanish national health system performance. To that end, we employ the database recently elaborated by the BBVA Fundation and IVIE [1], which covers 1991-2010. This database only includes information about the public health expenditure, which prevents us from analyzing the possible crowding effect between private and public health expenditure. By contrast, the span of the time series almost perfectly reflects the period in which the decentralization process occurred. Once we have selected the database, the next step is to analyze the possible presence of a single pattern of behavior in the Spanish regional per capita public health expenditures (HEPC) by testing for the null hypothesis of convergence. If we cannot reject it, then we can conclude that the health system is efficient in the sense that the regional governments offer the same health coverage using a similar amount of economic resources. But, if we reject this hypothesis, then we can find multiple patterns of behavior and these can be explained by some institutional factors, such as the ideology of the regional government party, which can allow us to conclude that the decentralization process has generated some disparities in the Spanish health system.

The paper is organized in four sections. In the first, the decentralization of the Spanish health system and the database we use are described. In the second, we test for convergence and identify several convergence clubs. The third section is devoted to the explanation of these clubs and, in particular, whether partisan variables exert a significant influence on health expenditures. The last section concludes.

\section{Public health expenditure in Spain}

The Spanish process of decentralization was accompanied by the General Health Law of 1986, which consolidated the universal health care system. In 2001, a new finance plan was approved which increased the fiscal responsibility of the Spanish regions and accelerated the process, which began in the early $80 \mathrm{~s}$ and finished around 2000. It was a complex process, negotiated case by case between the Central Government and the regional one, and it was characterized by a heterogeneity of mechanisms and finance systems for each region, as can be seen in Tamayo-Lorenzo [16], and it was strongly influenced by historical and political motivations, as Rico and Costa-Font (2005) point out.

This institutional context has been taken into account in the analysis of the determinants of regional health expenditure in Spain. We can cite the papers of Cantarero [17] Costa-Font and Rico [18] Costa-Font and Pons-Novell [15] Costa-Font and Moscone [19] Cantarero and Lago-Peñas [20] Lauridsen et al, [21] and Cantarero and Lago-Peñas [22]. The main conclusion that emerges from these papers is the influence of institutional and political factors, as well as some degree of spatial interdependence between neighboring regions.

In spite of their indubitable interest, we should point out that these papers employ a relatively short time span. The use of a longer database offers the opportunity of studying the evolution of the regional health expenditures from a time series point of view, allowing us to perform a convergence analysis. These reasons lead us to employ the database recently elaborated by the BBVA Fundation and IVIE [1]. It contains statistical information on HEPC in Spain in 1991-2010. We calculate, first, the real public health expenditure in 1991 prices for the 17 Spanish regions and, subsequently,
Table 1

PS methodology.

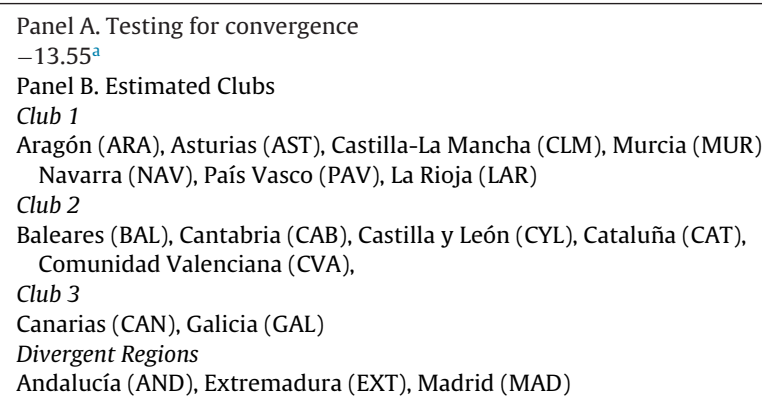

This table presents the results of applying the Phillips and Sul methodology to the per capita public health expenditure. Panel A shows the results of the PS log-t ratio employed for testing the null hypothesis of convergence. Panel B displays the members of each club, with the acronyms employed in Fig. 1 in parentheses.

a implies the rejection of the null hypothesis of convergence at a $5 \%$ significance level.

Table 2

Ordered probit estimation.

\begin{tabular}{ll}
\hline Explanatory variables & Estimated values \\
\hline GDP & -0.0002 \\
& $(-1.9)$ \\
RGOV & 3.70 \\
& $(4.1)$ \\
DEN & 0.01 \\
& $(2.3)$ \\
DISLAND & 0.88 \\
DFISCAL & $(1.8)$ \\
& -10.22 \\
Pseudo R & $(-11.9)$ \\
Percentage of cases correctly predicted & 0.59 \\
\hline
\end{tabular}

Robust $\mathrm{t}$-ratios in parentheses.

we employ the population data of the Spanish Institute of Statistics in per capita terms.

\section{Testing for convergence and clubs}

To determine whether the decentralization process has generated disparities, it is advisable to test for the null hypothesis of convergence. Whilst we could have followed several approaches, the characteristics of our sample lead us to employ the recent papers of Phillips and Sul [2,25], PS hereafter, which develop a very interesting framework to, first, test for the null hypothesis of convergence and, if this is rejected, to analyze the existence of clubs of regions that show similar patterns of behavior. We should note that the PS methodology has been previously employed to test for convergence in health expenditures. We can cite the papers of Panopoulou and Pantelidis [10] and Apergis et al. [23] in this regard, where an excellent explanation of the use of the PS methodology can be found. The results that we have obtained are reported in Tables 1 and 2.

Table 1 shows that the null hypothesis of convergence is rejected for HEPC and also confirms the presence of different clubs of regions that exhibit a similar pattern, a first step towards finding possible partisan health policies. In order to make the interpretation of the results easier, we have presented these clubs in colored maps in Fig. 1. First, we observe the presence of several convergence clubs, which shows that the regional health systems exhibit differences. This result is important because it may cast doubt on the capacity of the Spanish health system to provide identical coverage for everybody wherever they live. 


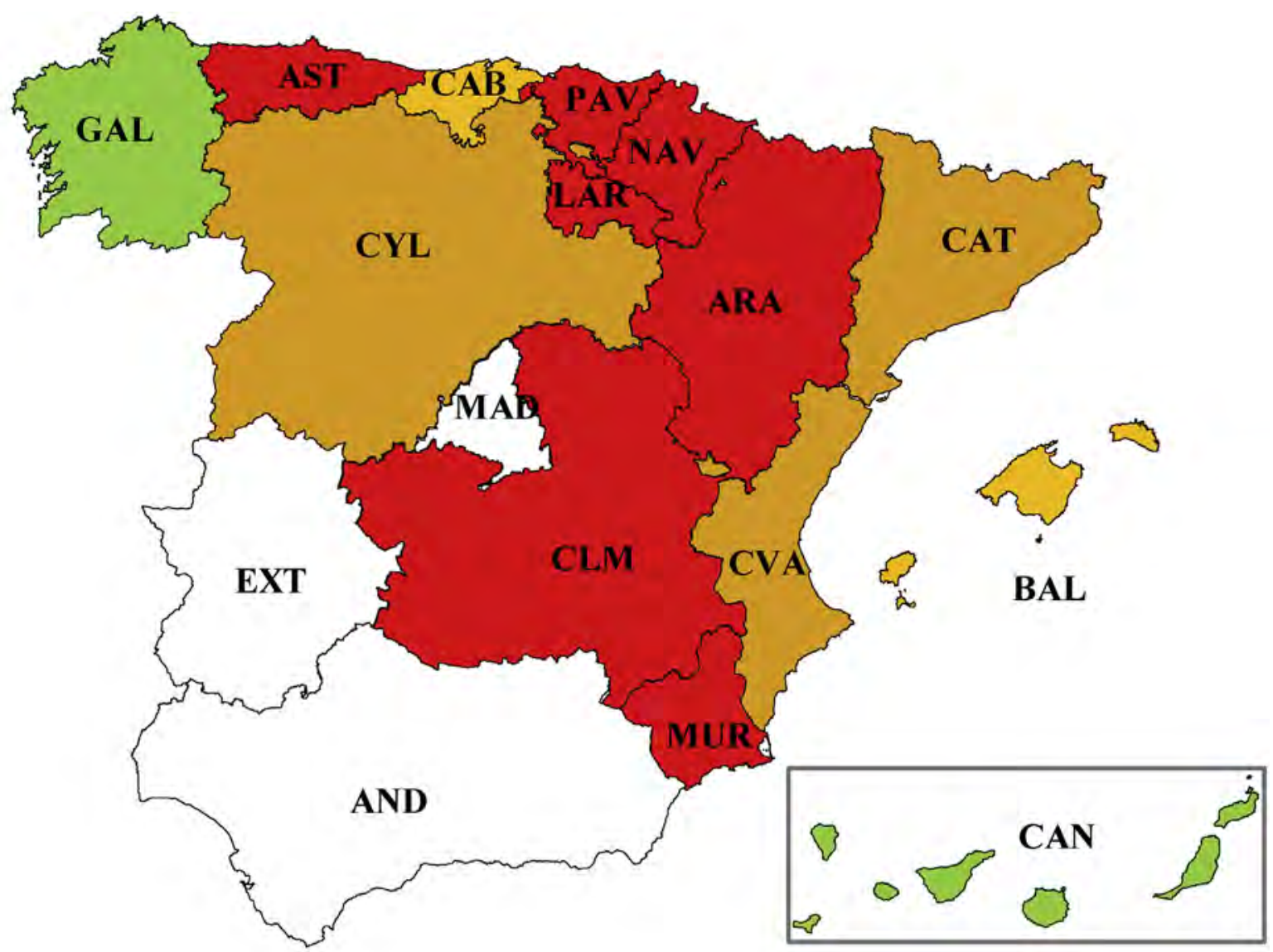

\section{Club 1}

Club 2

Club 3

\section{Divergent regions in white}

Fig. 1. Estimated clubs for per capita public health expenditure.

We should now consider the evolution of these clubs over time. In order to make this task easier, Fig. 2 reflects the arithmetic mean of the different clubs. We can observe that all the means grow, including those of the non-convergent regions (Andalucía, Extremadura and Madrid). Moreover, the growth speed does not vary very much between the clubs $(3.1,2.8$, and 3.0 , respectively, for clubs 1-3), while the non-convergent regions exhibit an average growth of 2.0, 3.7 and 1.3, respectively. However, the behavior at the end of the sample is different. The club means show a growth of 2.3, 2.8, and -1.4 for 2009-2010 whilst AND, EXT and MAD grow at $-2.7,0.4$ and -2.2 , respectively. Thus, the behavior is heterogeneous after the advent of the crisis. AND, MAD and the regions included in club 3 diminished their per capita public health expenditure whilst EXT maintains it. The rest have increased it at a rate similar to that of the pre-crisis period, especially the regions included in club 2, which showed a positive growth both in 2009 and in 2010. Thus, the behavior of the health expenditures at the end of the sample is important to understand the creation of the different clubs.

\section{Explanation of the clubs: is there partisan behavior?}

The previous section has shown that the HEPC of the Spanish regions shows different patterns of behavior, which could be understood as an inefficient use of public resources, in general, and of the health system in particular. Thus, it is interesting to investigate the sources of these differences. To that end, we should bear in mind that these differences can be explained by several factors, including geographical and socio-economic factors and partisan behavior. In order to capture these effects, we have selected the following variables, which are defined in Appendix 1:

- Geographical and spatial factors can be useful because the geomorphological characteristics of a region may condition the public health expenditures. For instance, a low population density may lead the regional government to increase expenditure. By contrast, if the population is concentrated, the control and optimization of the expenditure is clearly easier and, consequently, it should imply a reduction in health expenditures. Variables such 


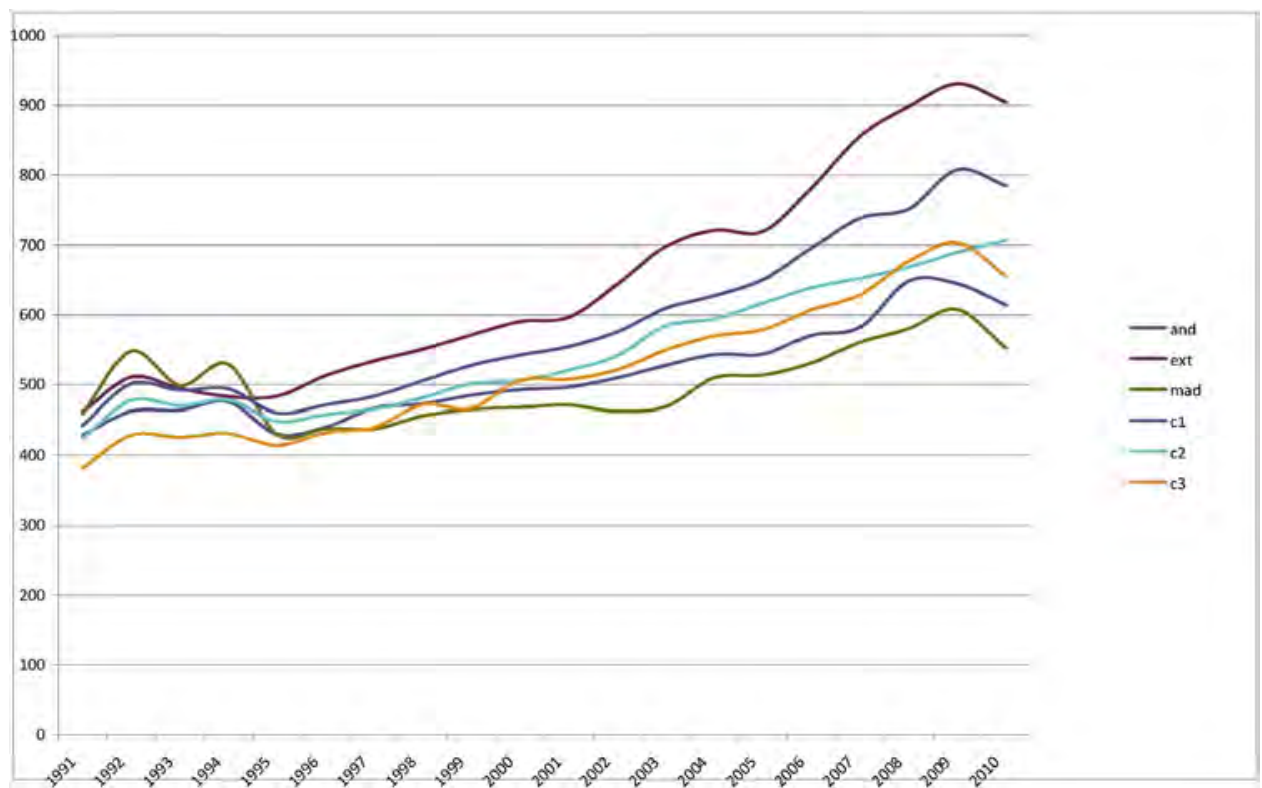

Fig. 2. Arithmetic mean of the values of clubs.

This figure presents the average values of the per capita health expenditure of regions in the different clubs.

as the area of the each region (SURF), measured in $\mathrm{km} \mathrm{[9],} \mathrm{and}$ its population density (DEN) may play an important role in this regard.

- Education: proxied by the percentage of the population with a bachelor degree (SUPSTUDIES) and without studies (ILLITERACY).

- Climatic factors: we use the level of humidity (HUM), days of rainfall (RAIN), and the temperature, in terms of days with temperatures below zero (TL0) and over 25 degrees (TG25).

- Population structure: as is well known, the composition of the population is also important to determine the volume of public health expenditure. A high proportion of dependent population may lead to bigger expenditures. To cover this possibility, we use the percentage of the population over 65 (G65) and under 15 (L15).

- Economic characteristics: health expenditures can be explained by per capita GDP at a macroeconomic level. To verify this, we use the average per capita GDP of each region (GDP).

- Fiscal regime: there are different fiscal regimes in Spanish regions. NAV and PAV have a special status, which may allow them to provide extra health benefits for their inhabitants. The dichotomous variable FISCAL takes value 1 for these two regions and 0 for the rest.

- Partisan decisions: we use the regional percentage of votes obtained by the most important right-wing party in Spain, the Popular Party, the percentage of years that this party has governed a region (PPGOV) and the percentage of years that any other right-wing party has governed a region (RWGOV). Furthermore, we should note the existence of some regional parties that play a very important role in the government of some regions and whose influence has sometimes reached the central government. In order to take into account their possible effect on public health expenditures, we have created the variable NAT which reflects the percentage of the votes for these regional parties.

- Dummy variables: we have also used some dummy variables for regions that are islands (DISLAND) and for regions made up of a single province (DSINGLE).

In order to analyze the interaction between the explanatory variables and club membership, an ordered probit model has been used to predict how regional characteristics affect the likelihood that any given region will be a member of any convergence club. Table 2 reports the results of the estimation of this model. The final specification has been selected by following a general-to-particular strategy, where the non-significant variables have been iteratively removed. The quality of the estimations is limited by the scant length of the sample, given that we have only 17 possible observations. However, we should note that some regions do not converge and are not included in any of the three estimated clubs. In these cases, and trying to avoid the loss of additional degrees of freedom, we have opted to include the non-convergent regions in the closest clubs. The cases of EXT and MAD seem to be clear and we have assigned them to clubs 1 and 3, respectively. The case of AND is a bit more problematic and, therefore, we have decided to omit it and the results presented in Table 2 only consider 16 regions. However, in order to analyze how sensitive the results are to the assignation of the non-convergent regions to the different clubs, Appendix 2 considers different alternatives though, as can be seen, the results obtained are similar to those presented here.

The estimated model presented in Table 2 includes the following variables: the per capita GDP of the region (GDP), the population density of the region (DEN), a dummy variable that takes value 1 if the region is an island (DISLAND), the fiscal dummy variable (FISCAL) and, the most important for our purposes, the percentage of years that the region has been governed by a right-wing party (RGOV).

The interpretation of the model is straightforward. The evolution of the economy is directly related to the HEPC and the higher the per capita GDP of a region, the greater the probability of it being assigned to clubs with the highest per capita health expenditures. By contrast, the higher the density, the higher the probability of it being assigned to clubs with low HEPC. Something similar occurs with BAL and CAN. Being an island implies a lower value of HEPC and, therefore, they are included in clubs 2 and 3. By contrast, the special fiscal system of the NAV and PAV regions favors their inclusion in club 1.

But, in our view, the most important result is that of the importance of the variable RGOV in order to explain the behavior of the different clubs. This variable measures the number of years that 
a right-wing party has governed a region and, consequently, the influence of its policies on public health expenditure. As we can see, the longer a right-wing party has governed a region, the lower the HEPC and, therefore, the higher the probability of being in clubs 2 and 3. Thus, we should conclude that there is a clear and significant partisan behavior in the evolution of Spanish HEPC.

\section{Conclusions}

Recent literature analyzes differences in health expenditure between territories and its convergence, as well as the main factors that explain it. This kind of study is especially relevant for Spain, given the political devolution process that has been developed in the last 20 years. Using public health expenditure data for Spanish regions over the period 1991-2010, our main contribution to the literature lies in the following findings.

First, our empirical results do not show the existence of full convergence in HEPC among the Spanish regions. However, we have found evidence that the evolution of the public health sector has generated a very heterogeneous health system in which we can observe at least three different patterns of behavior, with three additional regions, AND, EXT and MAD, growing independently from the rest. Therefore, we conclude that the decentralization process of the Spanish health system has created important disparities.

The analysis of the possible sources of this heterogeneity leads us to conclude that variables like the size of the economy, the fiscal benefits of some northern regions and the population density, which have traditionally been employed as determinants of health expenditure, are important in this regard. Very interestingly, we have found another variable that helps us to explain the disparities of the Spanish health system, namely, the percentage of years that a region has been governed by a right-wing party. This reinforces the idea that some institutional factors are important in order to explain the evolution of health expenditures, as suggested by Costa-Font and Pons (2007). In our case, we observe that the longer a region has been governed by a right-wing party, the lower the public health expenditure in this region.

This finding can be framed in the economic approach known as "the partisan approach". This approach focuses on the influence of party ideology, showing to what extent left-wing and right-wing politicians will provide policies that reflect the preferences of their partisans [12]. It predicts that left-wing parties promote policies that increase the growth of public health expenditure more than right-wing governments. Our results can be interpreted as empirical support for the partisan approach and, therefore, we should conclude that politics matters.

We should note that we are aware of the limitations of this study. In this regard, we should mention that the quality of the estimations is limited by the scant length of the sample, given that we have only 17 regions. Additionally, the database we use only considers public health expenditure. This restriction prevents us from analyzing the relationship between the private and the public health sector. These results would be of great interest and would complement those of Jiménez-Martín et al. [24]. Finally, our analysis offers evidence of the heterogeneous behavior of the Spanish health system, but we consider that some additional studies should be carried out in order to determine the consequences of these disparities. For instance, we consider it interesting to carry out further convergence analysis in terms of efficiency of spending, measuring it by way of, for instance, life expectancy or infant mortality. These last two questions are left for future research.

\section{Acknowledgements}

The authors acknowledge the financial support of the MEC (project ECO2015-65967-R), the Aragonese Government (project $\mathrm{S}-124)$ and the research group CASSETEM.

This paper has greatly benefited from the comments and suggestions of a referee and those of an associate editor. The usual disclaimer applies.

\section{References}

[1] BBVA Fundation, Ivie (Instituto Valenciano de Investigaciones Económicas), Base de datos disponible en Internet: Gasto sanitario público en España. Agosto de; 2013 http://www.fbbva.es.

[2] Phillips PCB, Sul D. Transition modeling and econometric convergence tests. Econometrica 2007;75(6):1771-855

[3] Newhouse JP. Medical care expenditure: a cross-national survey. Journal of Humman Resources 1977;12(1):115-25.

[4] Hartwig J, Sturm J-E. Robust determinants of health care expenditure growth. Applied Economics 2014;46(36):4455-74.

[5] Panopoulou E, Pantelidis T. Convergence in per capita health expenditures and health outcomes in the OECD countries. Applied Economics 2012;44(30):3909-20.

[6] Villaverde J, Maza A, Hierro M. Health care expenditure disparities in the European Union and underlying factors: a distribution dynamics approach. International Journal of Health Care Finance and Economics 2014;14:251-68.

[7] Payne JE, Anderson S, Lee J, Cho MH. Do per capita health care expenditures converge among OECD countries? Evidence from unit root tests with level and trend-shifts. Applied Economics 2015;47(52):5600-13.

[8] Wang Z. The convergence of health care expenditures in the US states. Health Economics 2009;18(1):55-70.

[9] Apergis N, Padhi P. Health expenses and economic growth: convergence dynamics across the Indian States. International Journal of Health Care Finance and Economics 2013;13(3-4):261-77

[10] Panopoulou E, Pantelidis T. Cross-state disparities in US health care expenditures. Health Economics 2013;22:451-65.

[11] Clemente J, Lazaro A, Montañés A, Working Paper Health expenditure convergence in the US States: does policy matter? University of Zaragoza; 2017.

[12] Potrafke N. The growth of public health expenditures in OECD countries: do government ideology and electoral motives matter? Journal of Health Economics 2010;29:97-810.

[13] Herwartz H, Theilen B. Health care and ideology: a reconsideration of political determinants of public healthcare funding in the OECD. Health Economics (United Kingdom) 2014;23(2):225-40.

[14] Liang LL, Mirelman AJ. Why some countries spend more for health? An assessment of sociopolitical determinants and international aid for government health expenditures. Social Science and Medicine 2014;114:161-8.

[15] Costa-Font J, Pons-Novell J. Public health expenditure and spatial interactions in a decentralized National Health System. Health Economics 2007;16:291-306.

[16] Tamayo-Lorenzo PA. Descentralization sanitaria y asignación de recursos en España: un análisis desde la perspectiva de la equidad. Información Comercial Española, ICE: Revista de Economía 2003;804:23-40.

[17] Cantarero D. Decentralization and health expenditure: the Spanish case. Applied Economic Letters 2005;12:963-6.

[18] Costa-Font J, Rico A. Devolution and the interregional inequalities in health and healthcare in Spain. Regional Studies 2006;40(8):875-87.

[19] Costa-Font J, Moscone F. The impact of decentralization and interterritorial interactions on Spanish health expenditure. Empirical Economics 2008;34:167-84.

[20] Cantarero D, Lago-Peñas S. "Decomposing the determinants of health care expenditure: the case of Spain. European Journal of Health Economics 2010;1:19-27.

[21] Lauridsen J, Bech M, Maté-Sánchez M. “Geographic and temporal heterogeneity in public prescription pharmaceutical expenditures in Spain. The Review of Regional Studies 2008;38(1):89-103.

[22] Cantarero D, Lago-Peñas S. "Decomposing the determinants of health care expenditure: the case of Spain. European Journal of Health Economics 2012;1:19-27.

[23] Apergis N, Chang T, Christou C, Gupta R. Convergence of health care expenditures across the US States: a reconsideration. Social Indicators Research 2015:1-14.

[24] Jiménez-Martín S, Labeaga-Azcona JM, Vilaplana-Prieto C. Interactions between private health and long-term care insurance and the effects of the crisis: evidence for Spain. Health economics 2016;25:159-79.

[25] Phillips PCB, Sul D. Economic transition and growth. Journal of Applied Econometrics 2009;24(7):1153-85 